\title{
Passive optical switches based on endohedral fullerenes
}

\author{
YongChang Dong, ${ }^{1}$ Deepika Saini, ${ }^{1}$ LUIS A. EChegoyen, ${ }^{2}$ And RAMAKrishna \\ PODILA ${ }^{1,3, *}$ \\ ${ }^{1}$ Department of Physics and Astronomy and Clemson Nanomaterials Center, Clemson University, Clemson, SC 29634, USA. \\ ${ }^{2}$ Department of Chemistry, University of Texas at EI Paso, EI Paso, TX 79968 USA. \\ ${ }^{3}$ Laboratory of Nano-biophysics, COMSET, Clemson University, Clemson, SC 29634, USA. \\ *Corresponding author: rpodila@g.clemson.edu.
}

Received XX Month XXXX; revised XX Month, XXXX; accepted XX Month XXXX; posted XX Month XXXX (Doc. ID XXXXX); published XX Month XXXX

Reverse saturable absorption in fullerenes has been widely used to realize excellent passive optical limiters for the visible region up to $650 \mathrm{~nm}$. However, there is still a need for passive optical switches and limiters with a low limiting threshold $\left(<0.5 \mathrm{~J} / \mathrm{cm}^{2}\right)$ and higher damage limits. The electronic structure of fullerenes can be modified either through doping or by the encapsulation of endohedral clusters to achieve exotic quantum states of matter such as superconductivity. Building on this ability, we show that the encapsulation of $\operatorname{Sc}_{3} \mathrm{~N}$, $\mathrm{Lu}_{3} \mathrm{~N}$ or $\mathrm{Y}_{3} \mathrm{~N}$ in $\mathrm{C}_{80}$ alters the HOMO-LUMO gap and leads to passive optical switches with a significantly low limiting threshold $\left(0.3 \mathrm{~J} / \mathrm{cm}^{2}\right)$ and a wider operation window (average pulse energy $>0.3 \mathrm{~mJ}$ in the ns regime).

OCIS codes: (140.3490) Lasers, distributed-feedback; (060.2420) Fibers, polarization-maintaining; (060.3735) Fiber Bragg gratings; (060.2370) Fiber optics sensors.

As our digital information needs continue to evolve at much faster rates than the growth of Si-based processors, the encroachment of light-based technologies into computing seems inevitable.[1-3] With the advent of lasers, photonic crystals, and optical diodes[3,4] photonic computing has made significant strides in information technology over the past 30 years. This continuing integration of light into all-optical computing, optoelectronic components, and emerging optogenetic technologies demands the ability to control and manipulate light in a predictable fashion or by design.[5] Although there are different dynamic methods (e.g., Faraday rotator) to manipulate light, the presence of multiple optical components and the necessity for active feedback/control (e.g., magnetic fields in Faraday rotator) impedes their immediate utilization in many technologies.[5] Alternatively, passive control and manipulation of light in all-optical switches, photonic diodes, and optical limiting could be achieved by directly using intrinsic non-linear optical properties of materials[4,5]. Of particular interest, in this work, is the use of all-optical switches and optical limiters for laser pulse-shaping and sensor protection. While an ideal optical switch is a nonlinear optical device that abruptly turns opaque (zero transmission) above a certain threshold intensity, an ideal optical limiter exhibits a linear (/non-zero and constant) transmission below (/above) the threshold (Fig. 1). In reality, when the leading edge of a fast optical pulse is comparable to the electron-electron scattering 
times (hundreds of fs to sub-ps) of the optical switch material, the pulse may partially pass through the optical switch before the material is non-linearly activated[5-7]. This yields a realistic switch/limiter response that is intermediate between an ideal limiter and an ideal switch, as shown in Fig. 1.

Realistic optical switches/limiters are useful in several applications, some of which include: i) pulse shaping where a long optical pulse with intensity spikes can be smoothed by selectively attenuating the high-intensity spikes that exclusively elicit non-linear responses in the switch[5], and ii) sensor protection for extending the dynamic range of the sensor by mitigating light-induced damage.[5,8-12] In regards to sensor protection, the extensive deployment of lasers poses a serious threat for sensitive optical and electronic components/devices including eyes now, more than ever. Indeed, the strong absorption of biomolecules in the near-infrared (NIR) region exacerbates the possibility of NIR laser-induced injuries and accidents, making the need for effective protection against lasers a priority.[13,14] The emergence of various nanomaterials and their heterostructures with unique non-linear properties (e.g., reverse saturable absorption in $\mathrm{C}_{60}$ ) led to the realization of enhanced optical limiting materials.[6,8-12,15-24] Although nanomaterials display an improved optical limiting threshold (the input fluence at which the transmittance falls to $50 \%$ of its initial value) at higher input fluences $>1 \mathrm{~J} / \mathrm{cm}^{2}$ (Table 1), it is challenging to achieve excellent optical limiting capability in the low fluence regime $\left(<1 \mathrm{~J} / \mathrm{cm}^{2}\right)$.[8] Furthermore, realistic optical switches should also exhibit a rapid decrease in transmission (ideally, the transmission should abruptly drop to zero above the threshold intensity, as shown in Fig. 1) in addition to a low-threshold.[5] In this regard, others and we previously found that tailoring the electronic band structure of nanomaterials via dopants \& defects (e.g., oxidized graphene/B- or N-doping), and modulating electron scattering mechanisms through heterostructured geometries (e.g., Au nanoparticles of reduced graphene oxide) shows excellent promise for controlling non-linear optical properties.[8,25-28] Building on these results, in this article, we demonstrate the use of thermally stable endohedral cluster fullerenes $\left(\mathrm{Sc}_{3} \mathrm{~N} @ \mathrm{C}_{80}, \mathrm{Lu}_{3} \mathrm{~N} @ \mathrm{C}_{80}\right.$ and $\left.\mathrm{Y}_{3} \mathrm{~N} @ \mathrm{C}_{80}\right)$ as potential passive realistic optical switch/limiter materials with low-fluence threshold and high-damage limits for pulsed ns $1064 \mathrm{~nm}$ wavelength. The excellent match between the HOMO-LUMO gap in $\mathrm{Lu}_{3} \mathrm{~N} @ \mathrm{C}_{80}$ and $1064 \mathrm{~nm}$ leads to the realization of thresholds as low as $\sim 0.3 \mathrm{~J} / \mathrm{cm}^{2}$, which are at least an order of magnitude lower compared to many nanomaterials, particularly $\mathrm{C}_{60}$ (Table 1). More importantly, the nonlinear transmission through $\mathrm{Lu}_{3} \mathrm{~N} @ \mathrm{C}_{80}$ decreases much more rapidly than for other nanomaterials, making it an ideal candidate for realistic optical switching. In addition to the low-fluence, our experiments show that $\mathrm{Sc}_{3} \mathrm{~N} @ \mathrm{C}_{80}, \mathrm{Lu}_{3} \mathrm{~N} @ \mathrm{C}_{80}$, and $\mathrm{Y}_{3} \mathrm{~N} @ \mathrm{C}_{80}$ can withstand high nanosecond pulsed-laser energies $>0.5 \mathrm{~mJ}$ (average pulse energy) which is at least 10-100 times higher than for other metallic and dielectric materials[29,30] and is on par with high-power Er/Yb doped optical fibers.[31-34]

$\mathrm{C}_{60}$ (Carbon 60, 99.95+ \%, ultra pure Vacuum oven dried) was purchased from SES research, Houston, TX. $\mathrm{Sc}_{3} \mathrm{~N} @ \mathrm{C}_{80}, \mathrm{Lu}_{3} \mathrm{~N} @ \mathrm{C}_{80}$ and $\mathrm{Y}_{3} \mathrm{~N} @ \mathrm{C}_{80}$ were obtained using an arc-discharge process described earlier.[35] To gauge the non-linear optical performance of $\mathrm{C}_{60}, \mathrm{Sc}_{3} \mathrm{~N} @ \mathrm{C}_{80}, \mathrm{Lu}_{3} \mathrm{~N} @ \mathrm{C}_{80}$ and $\mathrm{Y}_{3} \mathrm{~N} @ \mathrm{C}_{80}$ we used a conventional open aperture Z-scan technique described earlier.[8,36] All measurements were performed with linearly polarized 7 ns optical pulses from a Q-switched frequency-doubled Nd:YAG laser at 1064nm. For our Z-scan setup, the laser beam was focused by a converging lens with a focal length of $20 \mathrm{~cm}$ on to a stable dispersion that was held in the $1 \mathrm{~mm}$ quartz cuvette (100-QS Hellma ${ }^{\circledR}$ Analytics) and translated across the focal plane in the beam direction ( $\mathrm{Z}$ direction). At each $\mathrm{Z}$ position, the position dependent transmittance was measured using a calibrated photodetector (RjP-7620, Laserprobe, Inc.) to obtain the Z-scan curves shown in Figs. 2 and 3. $\mathrm{C}_{60}, \mathrm{Sc}_{3} \mathrm{~N} @ \mathrm{C}_{80}, \mathrm{Lu}_{3} \mathrm{~N} @ \mathrm{C}_{80}$ and $\mathrm{Y}_{3} \mathrm{~N} @ \mathrm{C}_{80}$ were suspended in toluene at $0.5 \mathrm{mg} / \mathrm{ml}$ concentration using aqueous bath sonication (Branson Aquasonic) for 30 minutes. 
The open aperture Z-scan curves (shown in Fig. 2) often emerge from one or multiple non-linear phenomena (e.g., saturable, reverse saturable, or multi-photon absorption) occurring simultaneously in the photo-excited material under study. For instance, the nonlinear transmission for a sample exhibiting exclusively reverse saturable or two-photon absorption (RSA or 2PA) processes (e.g., $\mathrm{C}_{60}$ in Fig. 2a) is given by equation (1)

$$
T=(1-R)^{2} e^{\frac{-\alpha_{0} L}{\sqrt{\pi q_{0}}}} \int_{-\infty}^{+\infty} \ln \left(1+q_{0}^{2} e^{-t^{2}}\right) d t
$$

where $L$ and $R$ are the sample length $(1 \mathrm{~mm})$ and surface reflectivity, respectively. In $\mathrm{Eq} 1, \alpha_{0}$ is the unsaturated linear absorption coefficient, $q_{0}$ is given by $\beta(1-R) I_{0} L_{\text {eff, }}$ where $\beta$ is the absorption coefficient for a RSA/2PA process. The effective length $L_{\text {eff }}$ is given by $\left(1-\exp \left(\epsilon_{0} L\right)\right) / \alpha_{0}$. For materials that simultaneously exhibit more than one NLO process, like saturable absorption competing with a RSA/2PA process (e.g., $\mathrm{Sc}_{3} \mathrm{~N} @ \mathrm{C}_{80}, \mathrm{Lu}_{3} \mathrm{~N} @ \mathrm{C}_{80}$ and $\mathrm{Y}_{3} \mathrm{~N} @ \mathrm{C}_{80}$ in Fig. 2b, c, d), the nonlinear transmission of the sample is best described by the propagation equation as

$$
\frac{d I}{d z^{\prime}}=-\frac{\alpha_{0} I}{1+\frac{I}{I_{s}}}-\beta I^{2}(2)
$$

where $I_{\mathrm{S}}$ is the saturation absorption intensity. RSA is a non-linear optical phenomenon, which occurs when the photoexcited state exhibits higher absorption cross-section than the ground state. As shown in Fig. 2a, it is well known that $\mathrm{C}_{60}$ exhibits RSA,[6,10,21] when exposed to ns pulses, due to the excitation of groundstate electrons (in singlet state $S_{0}$ ) to the long-lived lowest triplet state $\mathrm{T}_{1}$ (which has a higher absorption cross-section than $S_{0}$ ) through a fast and efficient intersystem crossing via a singlet state $S_{1}$. Our Z-scan curves for $\mathrm{C}_{60}$ (Fig. 2a) could be fitted well using a two-photon absorption process (Eq. 1) with $\beta \sim 4.5 \times 10^{-9}$ $\mathrm{cm} / \mathrm{W}$, concurring with the previously observed properties of $\mathrm{C}_{60}$.[37] Although the strong linear optical absorption of $S_{0}-S_{1}$ states (see Fig. 3a) leads to efficient RSA and optical limiting up to $\sim 650 \mathrm{~nm}$, the optical switching/limiting behavior of $\mathrm{C}_{60}$ is poor for near-infrared wavelengths such as $1064 \mathrm{~nm}(1.16 \mathrm{eV})$ : a very commonly used ns pulsed laser wavelength.[38] To overcome this apparent challenge, we used TNEFs which exhibits a HOMO-LUMO gap $\sim 1.9-2.1 \mathrm{eV}$ that can near-resonantly couple to $1064 \mathrm{~nm}(\sim 1.16$ eV)through 2PA.[35] The difference in linear absorption characteristics of TNEFs and $\mathrm{C}_{60}$ is clearly evident from the photographs of $\mathrm{C}_{60}$ and TNEFs solutions in toluene shown in the inset of Fig. 3a. Previously, it was demonstrated that the electronic structure of fullerenes could be modified through nitrogen, alkali and rareearth alkali metals doping or by the encapsulation of endohedral atoms/clusters to achieve exotic quantum states of matter such as superconductivity.[39-41] These changes in the electronic properties could then also be used to realize passive optical switches, as demonstrated in Fig. 3b. The Z-scan curves for $\mathrm{Sc}_{3} \mathrm{~N} @ \mathrm{C}_{80}$, $\mathrm{Lu}_{3} \mathrm{~N} @ \mathrm{C}_{80}$ and $\mathrm{Y}_{3} \mathrm{~N} @ \mathrm{C}_{80}$ (Fig. 2b-d) exhibited 2PA with some saturable absorption (i.e., higher transmittance at non-linear intensities) with high $I_{s}$ values (numerically fitted using Eq. 2). The 2PA coefficient $\beta$ for $\mathrm{Sc}_{3} \mathrm{~N} @ \mathrm{C}_{80}$ was found to be $\sim 5 \times 10^{-9} \mathrm{~cm} / \mathrm{W}$, (for $\mathrm{Lu}_{3} \mathrm{~N} @ \mathrm{C}_{80} \sim 6 \times 10^{-9} \mathrm{~cm} / \mathrm{W}$ and $\mathrm{Y}_{3} \mathrm{~N} @ \mathrm{C}_{80} \sim 7 \times 10^{-9} \mathrm{~cm} / \mathrm{W}$ ) which are higher than that of $\mathrm{C}_{60}$. This increase in $\beta$ may be attributed to the lower HOMO-LUMO gap of $\mathrm{Sc}_{3} \mathrm{~N} @ \mathrm{C}_{80}, \sim 1.9 \mathrm{eV}[35], \mathrm{Lu}_{3} \mathrm{~N} @ \mathrm{C}_{80}, \sim 2.05 \mathrm{eV}$, and $\mathrm{Y}_{3} \mathrm{~N} @ \mathrm{C}_{80}, \sim 2.04 \mathrm{eV}$ compared to that for $\mathrm{C}_{60}, \sim 2.48 \mathrm{eV}$. It should be noted that the HOMO-LUMO gaps were obtained from the density functional theory calculations described in Ref. 29. The non-linear transmission of TNEFs decreases much more rapidly than for $\mathrm{C}_{60}$ (Fig. 3b) closer to the behavior of a realistic optical switch (Fig. 1). This rapid change in non-linear transmission could plausibly be attributed to: i) fast carrier relaxation rates $(\sim 100$ ps resulting from the presence of tri metallic nitrides) compared to $\mathrm{C}_{60}(1.5 \mathrm{~ns}),[42]$ which in turn can lead to multiple excitation/de-excitations within the ns pulse width, and ii) the charge transfer between photo-excited fullerene cage to $\mathrm{Sc}_{3} \mathrm{~N}$ which rapidly depletes the excited state population to promote more electrons from the ground state through 
photo-excitations.[43] A very weak saturable absorption component $\left(I_{\mathrm{s}} \sim 10^{13}-10^{14} \mathrm{~W} / \mathrm{m} 2\right)$ was observed for $\mathrm{Sc}_{3} \mathrm{~N} @ \mathrm{C}_{80}$ (Fig. 3b). Previously, Chemla et al. proposed that $I_{s}$ in quantum wells and dots is mainly determined by a carrier-relaxation time through an inverse relation.[44] Although the exact electronic states involved in saturable absorptions cannot be identified solely through the Z-scan, the high-magnitude of $I_{s}$ for

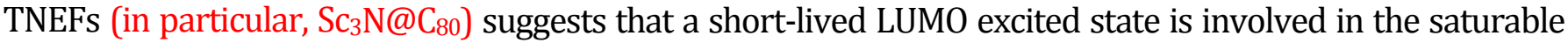
absorption, concurring with the data above. Interestingly, the optical switching/limiting response of TNEFs is highly prominent and exceeds the performance of $\mathrm{C}_{60}$ at $1064 \mathrm{~nm}$ despite the presence of a saturable absorption component. As shown in Fig. 4a, we observed that the linear transmittance at $1064 \mathrm{~nm}$ of $\mathrm{Sc}_{3} \mathrm{~N} @ \mathrm{C}_{80}$ exhibits a rapid decrease as a function of concentration while it remains fairly in the same range for $\mathrm{C}_{60}$ and other TNEFs. This trend indicates possible intermolecular interactions in $\mathrm{Sc}_{3} \mathrm{~N} @ \mathrm{C}_{80}$ that could increase the absorption at $1064 \mathrm{~nm}$. In order to account for such concentration dependent effects, we also performed Z-scan experiments (Fig. 4b) at similar linear transmittance $(\sim 75 \pm 5 \%)$ for all samples, in addition to the data at $0.5 \mathrm{mg} / \mathrm{ml}$ concentration (cf. Fig. 2). We found optical limiting in TNEFs $\sim 0.3-0.5 \mathrm{~J} / \mathrm{cm}^{2}$ at $75 \%$ linear transmission while $\mathrm{C}_{60}$ did not exhibit $<50 \%$ transmittance concurring with the results described in Fig. 2 (i.e., at $0.5 \mathrm{mg} / \mathrm{ml}$ concentration).

In summary, the lower HOMO-LUMO gap and intermolecular interactions in TNEFs allows strong nonlinear absorption of $1064 \mathrm{~nm}$ wavelength in the ns regimen. Furthermore, the presence of the previously described charge transfer between the fullerene cage and trimetallic nitride is expected to increase the nonlinear absorption at rates fast enough to provide a realistic optical switch response in TNEFs. Our results show that the TNEFs are excellent optical limiters with a low limiting threshold $\sim 0.3 \mathrm{~J} / \mathrm{cm}^{2}$ at $1064 \mathrm{~nm}$, high damage threshold $>0.3 \mathrm{~mJ}$, and can function as a realistic passive optical switches with a fast increase in absorption with increasing intensity.

Funding. National Science Foundation, grants DMR-1205302 (PREM Program) and CHE-1408865; The Robert A. Welch Foundation, grant \# AH-0033.

Acknowledgment. R.P. and Y.C.D. would like to thank Prof. Apparao M. Rao, Clemson University, Dr. Benoy Anand, University of Texas at Dallas, and Dr. V. S. Muthukumar, Sri Sathya Sai Institute of Higher Learning, India for their valuable inputs for fitting the Z-scan data. L. E. wishes to thank the US National Science Foundation, grants DMR-1205302 (PREM Program) and CHE-1408865 and the Robert A. Welch Foundation, grant \# AH-0033, for generous financial support.

\section{References}

[1] A. Biberman, K. Bergman, Optical interconnection networks for high-performance computing systems., Rep. Prog. Phys. 75 (2012) 046402. doi:10.1088/0034-4885/75/4/046402.

[2] A. Aspuru-Guzik, P. Walther, Photonic quantum simulators, Nat. Phys. 8 (2012) 285-291.

[3] D. Woods, T.J. Naughton, Optical computing: Photonic neural networks, Nat. Phys. 8 (2012) 257259.

[4] B. Anand, R. Podila, K. Lingam, S.R. Krishnan, S. Siva Sankara Sai, R. Philip, et al., Optical diode action from axially asymmetric nonlinearity in an all-carbon solid-state device, Nano Lett. 13 (2013) 5771-5776. doi:10.1021/nl403366d. 
[5] L.W. Tutt, T.F. Boggess, A review of optical limiting mechanisms and devices using organics, fullerenes, semiconductors and other materials, Prog. Quantum Electron. 17 (1993) 299-338. doi:10.1016/0079-6727(93)90004-S.

[6] A. Kost, L. Tutt, M.B. Klein, T.K. Dougherty, W.E. Elias, Optical limiting with C(60) in polymethyl methacrylate., Opt. Lett. 18 (1993) 334-336.

[7] M. Yoda, Encyclopedia of Nanotechnology, 2012. doi:10.1007/978-90-481-9751-4.

[8] P. Pradhan, R. Podila, M. Molli, A. Kaniyoor, V. Sai Muthukumar, S. Siva Sankara Sai, et al., Optical limiting and nonlinear optical properties of gold-decorated graphene nanocomposites, Opt. Mater. (Amst). 39 (2015) 182-187. doi:10.1016/j.optmat.2014.11.023.

[9] W. Jia, E.P. Douglas, F. Guo, W. Sun, Optical limiting of semiconductor nanoparticles for nanosecond laser pulses, Appl. Phys. Lett. 85 (2004) 6326-6328. doi:10.1063/1.1836871.

[10] Y. Sun, J.E. Riggs, B. Liu, Optical Limiting Properties of [60]Fullerene Derivatives, Chem. Mater. 9 (1997) 1268-1272. http://pubs.acs.org/doi/abs/10.1021/cm960650v.

[11] Y.-P. Sun, J.E. Riggs, Organic and inorganic optical limiting materials. From fullerenes to nanoparticles, Int. Rev. Phys. Chem. 18 (1999) 43-90.

[12] J. Wang, W.J. Blau, Inorganic and hybrid nanostructures for optical limiting, J. Opt. A Pure Appl. Opt. 11 (2009) 024001.

[13] D.J. Payne, R. a Hopkins, B.G. Eilert, G.D. Noojin, D.J. Stolarski, R.J. Thomas, et al., Comparative study of laser damage threshold energies in the artificial retina., J. Biomed. Opt. 4 (1999) 337-44. doi:10.1117/1.429935.

[14] R. Brinkmann, G. Hüttmann, J. Rögener, J. Roider, R. Birngruber, C.P. Lin, Origin of retinal pigment epithelium cell damage by pulsed laser irradiance in the nanosecond to microsecond time regimen, Lasers Surg. Med. 27 (2000) 451-464.

[15] N. MacKiewicz, T. Bark, B. Cao, J.A. Delaire, D. Riehl, W.L. Ling, et al., Fullerene-functionalized carbon nanotubes as improved optical limiting devices, Carbon N. Y. 49 (2011) 3998-4003.

[16] K.M. Nashold, D.P. Walter, Investigations of optical limiting mechanisms in carbon particle suspensions and fullerene solutions, J. Opt. Soc. Am. B. 12 (1995) 1228.

[17] J.E. Riggs, Y.-P. Sun, Optical limiting properties of mono- and multiple-functionalized fullerene derivatives, J. Chem. Phys. 112 (2000) 4221-4230.

http://reichling.physik.uos.de/download_paper.php?paper=JChemPhys112p4221(2000)_Riggs.pdf

[18] C. Liu, G. Zhao, Q. Gong, K. Tang, X. Jin, P. Cui, et al., Optical limiting property of molybdenum complex of fullerene C70, Opt. Commun. 184 (2000) 309-313.

[19] A.W. Allaf, M.D. Zidan, Optical limiting behavior of new fullerene derivatives, Opt. Lasers Eng. 43 (2005) 57-62.

[20] A.R. Kost, J.E. Jensen, R.O. Loufty, J.C. Wither, Optical limiting with higher fullerenes, Appl. Phys. B Lasers Opt. 80 (2005) 281-283.

[21] S.S. Harilal, C. V. Bindhu, V.P.N. Nampoori, C.P.G. Vallabhan, Optical limiting and thermal lensing studies in C[sub 60], J. Appl. Phys. 86 (1999) 1388. doi:10.1063/1.370899.

[22] V.S. Muthukumar, J. Reppert, C.S.S. Sandeep, S.S.R. Krishnan, R. Podila, N. Kuthirummal, et al., Optical limiting properties of CdS nanowires, Opt. Commun. 283 (2010) 4104-4107. doi:10.1016/j.optcom.2010.06.020.

[23] Q. Chang, C. Chang, X. Zhang, H. Ye, G. Shi, W. Zhang, et al., Enhanced optical limiting properties in suspensions of CdO nanowires, Opt. Commun. 274 (2007) 201-205.

doi:10.1016/j.optcom.2007.01.064. 
[24] H. Pan, W. Chen, Y.P. Feng, W. Ji, J. Lin, Optical limiting properties of metal nanowires, Appl. Phys. Lett. 88 (2006) 17-20. doi:10.1063/1.2208549.

[25] B. Anand, R. Podila, P. Ayala, L. Oliveira, R. Philip, S.S.S. Sai, et al., Nonlinear optical properties of boron doped single-walled carbon nanotubes., Nanoscale. 5 (2013) 7271-6. doi:10.1039/c3nr01803b.

[26] R. Podila, B. Anand, J.P. West, R. Philip, S.S.S. Sai, J. He, et al., Evidence for surface states in pristine and Co-doped ZnO nanostructures: magnetization and nonlinear optical studies., Nanotechnology. 22 (2011) 095703.

[27] B. Karthikeyan, C.S.S. Sandeep, T. Pandiyarajan, P. Venkatesan, R. Philip, Optical and nonlinear absorption properties of Na doped ZnO nanoparticle dispersions, Appl. Phys. Lett. 95 (2009).

[28] J. Zhao, X. Chen, J.R.H. Xie, Optical properties and photonic devices of doped carbon nanotubes, Anal. Chim. Acta. 568 (2006) 161-170.

[29] C.S. Kumar, Mixed metal nanomaterials, 3rd ed., John Wiley \& SOns, 2009.

[30] C.M. Aguirre, C.E. Moran, J.F. Young, N.J. Halas, Laser-induced reshaping of metallodielectric nanoshells under femtosecond and nanosecond plasmon resonant illumination, J. Phys. Chem. B. 108 (2004) 7040-7045.

[31] C.D. Brooks, F. Di Teodoro, High peak power operation and harmonic generation of a singlepolarization, Yb-doped photonic crystal fiber amplifier, Opt. Commun. 280 (2007) 424-430.

[32] S. Desmoulins, F. Di Teodoro, High-gain Er-doped fiber amplifier generating eye-safe MW peakpower, mJ-energy pulses., Opt. Express. 16 (2008) 2431-2437.

[33] M.-Y. Cheng, Y.-C. Chang, A. Galvanauskas, P. Mamidipudi, R. Changkakoti, P. Gatchell, Highenergy and high-peak-power nanosecond pulse generation with beam quality control in 200microm core highly multimode Yb-doped fiber amplifiers., Opt. Lett. 30 (2005) 358-360. doi:10.1364/OL.30.000358.

[34] A. V. Smith, B.T. Do, G.R. Hadley, R.L. Farrow, Optical damage limits to pulse energy from fibers, IEEE J. Sel. Top. Quantum Electron. 15 (2009) 153-158.

[35] J.R. Pinzón, C.M. Cardona, M.Á. Herranz, M.E. Plonska-Brzezinska, A. Palkar, A.J. Athans, et al., Metal nitride cluster fullerene M3N@C80 (M = Y, Sc) based dyads: Synthesis, and electrochemical, theoretical and photophysical studies, Chem. - A Eur. J. 15 (2009) 864-877. doi:10.1002/chem.200801559.

[36] M. Sheik-Bahae, A.A. Said, T.-H. Wei, D.J. Hagan, E.W. Van Stryland, Sensitive measurement of optical nonlinearities using a single beam, IEEE J. Quantum Electron. 26 (1990) 760-769. doi:10.1109/3.53394.

[37] S. Couris, E. Koudoumas, A.A. Ruth, S. Leach, in toluene solution, J. Phys. B At. Mol. Opt. Phys. 28 (1999) 4537-4554. doi:10.1088/0953-4075/28/20/015.

[38] S.R. Mishra, H.S. Rawat, S.C. Mehendale, Reverse saturable absorption and optical limiting in C 60 solution in the near-infrared, Appl. Phys. Lett. 71 (1997) 46-48.

[39] M.S. Dresselhaus, G. Dresselhaus, A.M. Rao, P.C. Eklund, Optical properties of C60 and related materials, Synth. Met. 78 (1996) 313-325.

[40] S. Fleischer, B. Pevzner, D. Dougherty, H. Zeiger, G. Dresselhaus, M. Dresselhaus, et al., Ultrafast dynamics of superconducting K3C60 and Rb3C60, Phys. Rev. B. 62 (2000) 1366-1378.

[41] P.W. Stephens, L. Mihaly, P.L. Lee, R.L. Whetten, S.-M. Huang, R. Kaner, et al., Structure of singlephase superconducting K3C60, Nature. 351 (1991) 632-634.

[42] M. Krause, H. Kuzmany, P. Georgi, L. Dunsch, K. Vietze, G. Seifert, Structure and stability of endohedral fullerene Sc3N@C80: A Raman, infrared, and theoretical analysis, J. Chem. Phys. 115 (2001) 6596-6605. 
[43] J.R. Pinzón, D.C. Gasca, G.S. Shankara, G. Bottari, T. Torres, D.M. Guldi, et al., Photoinduced Charge Transfer and Electrochemical Properties of Triphenylamine Ih-Sc3 N@C80 Donor-Acceptor Conjugates, J. Am. Chem. Soc. 131 (2009) 7727-7734. doi:10.1021/ja900612g.Photoinduced.

[44] D.S. Chemla, D.A.B. Miller, Room-temperature excitonic nonlinear-optical effects in semiconductor quantum-well structures, J. Opt. Soc. Am. B. 2 (1985) 1155. 
Figures and captions:

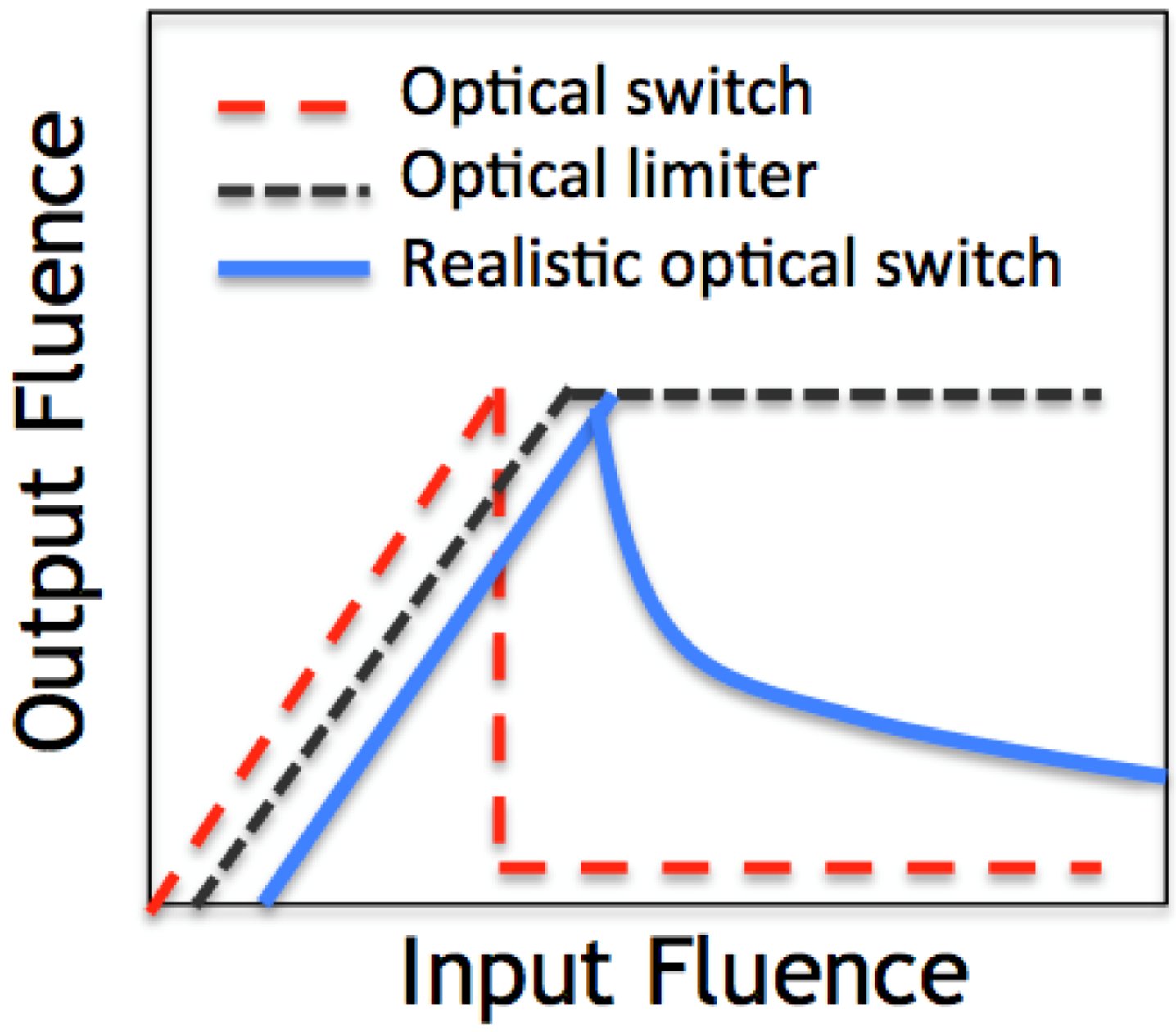

Fig. 1. A schematic showing the optical response for an ideal optical limiter (dashed black line), an ideal optical switch (red dashed line), and a realistic passive optical switch as a function of input fluence. 

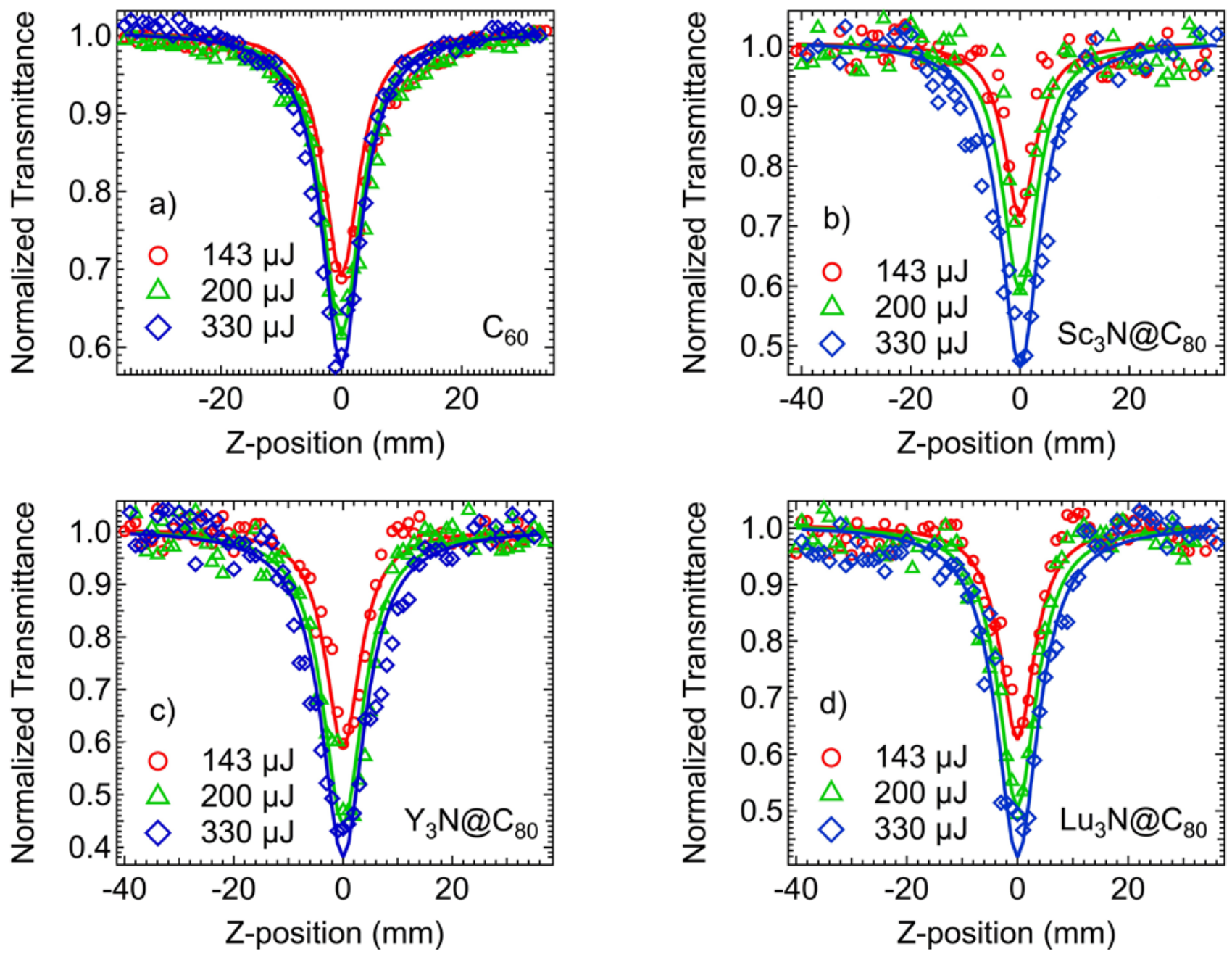

Fig. 2. Z-scan curves for $\mathrm{C}_{60}(\mathrm{a})$ and $\mathrm{Sc}_{3} \mathrm{~N} @ \mathrm{C}_{80}$ (b) at different energies clearly show a valley indicating reverse saturable/two-photon response. The markers represent the experimental data and the solid lines are experimental fits obtained by solving a non-linear light propagation equation. 

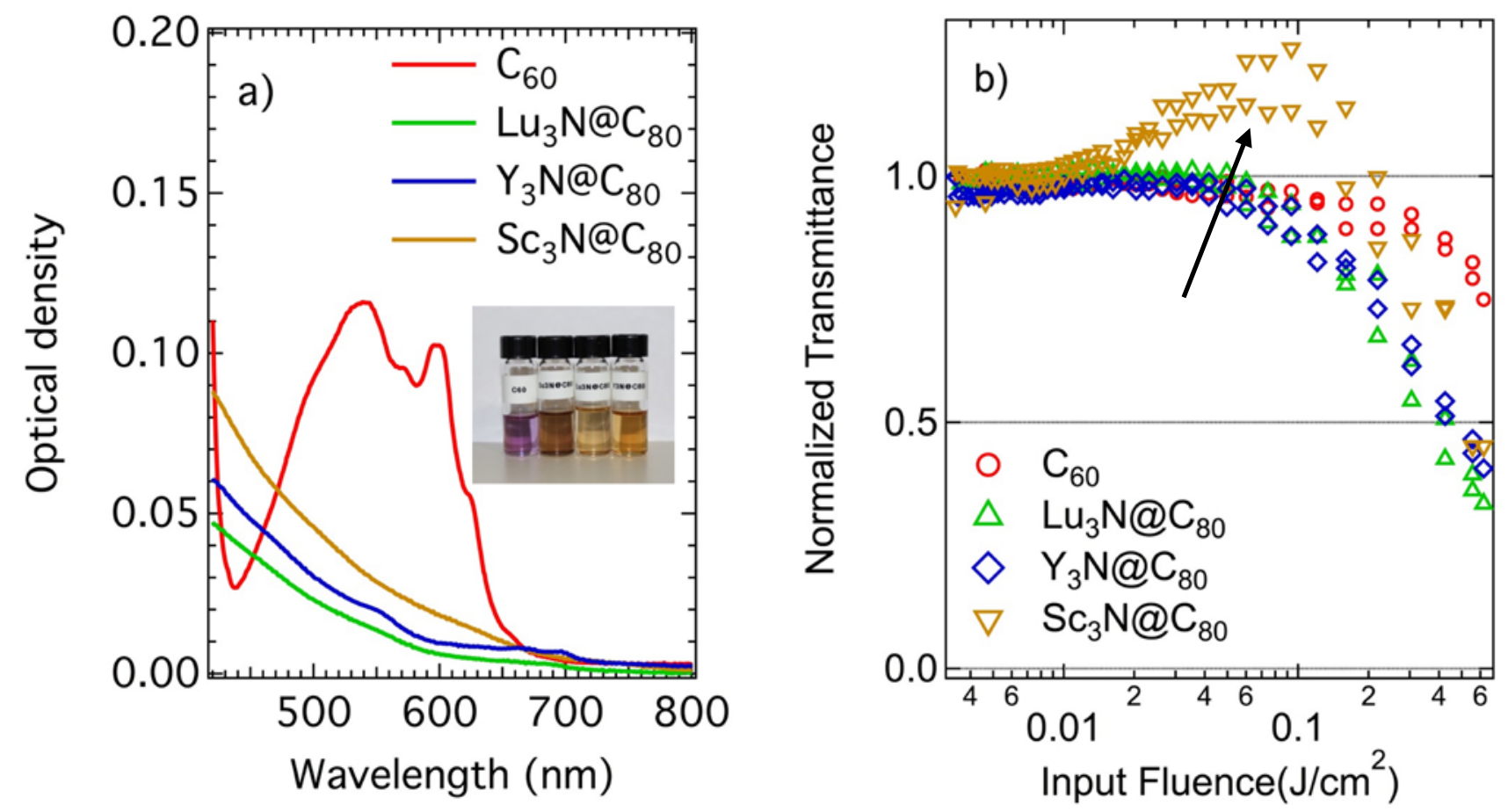

Fig. 3. (a) UV-Visible absorption spectrum for $\mathrm{C}_{60}, \mathrm{Sc}_{3} \mathrm{~N} @ \mathrm{C}_{80}, \mathrm{Lu}_{3} \mathrm{~N} @ \mathrm{C}_{80}$ and $\mathrm{Y}_{3} \mathrm{~N} @ \mathrm{C}_{80}$. The inset shows a digital photograph of $\mathrm{C}_{60}, \mathrm{Sc}_{3} \mathrm{~N} @ \mathrm{C}_{80}, \mathrm{Lu}_{3} \mathrm{~N}$ and $\mathrm{Y}_{3} \mathrm{~N}$ (from left to right) exhibiting different colors due to different HOMO-LUMO gaps. (b) The non-linear optical response curve obtained (same concentration, $0.5 \mathrm{mg} / \mathrm{ml}$ ) using the Z-scan method (1064 nm, $7 \mathrm{~ns}$ ) shows a rapid decrease in transmission for $\mathrm{Sc}_{3} \mathrm{~N} @ \mathrm{C}_{80}$, $\mathrm{Lu}_{3} \mathrm{~N} @ \mathrm{C}_{80}$ and $\mathrm{Y}_{3} \mathrm{~N} @ \mathrm{C}_{80}$ relative to $\mathrm{C}_{60}$ at higher intensities similar to a realistic optical switch (cf. Fig. 1). The dashed line indicates 50\% transmittance of the incident light. $\mathrm{Sc}_{3} \mathrm{~N} @ \mathrm{C}_{80}, \mathrm{Lu}_{3} \mathrm{~N} @ \mathrm{C}_{80}$ and $\mathrm{Y}_{3} \mathrm{~N} @ \mathrm{C}_{80}$ reach the $50 \%$ transmission (shown by dashed line) around a low threshold $0.3 \sim 0.5 \mathrm{~J} / \mathrm{cm}^{2}$ while $\mathrm{C}_{60}$ does not exhibit optical limiting (i.e., normalized transmittance remains $>50 \%$ ) below $1 \mathrm{~J} / \mathrm{cm}^{2}$. The arrow in (b) shows saturable absorption (normalized transmittance $>100 \%$ relative to linear transmittance) for $\mathrm{Sc}_{3} \mathrm{~N} @ \mathrm{C}_{80}$. 

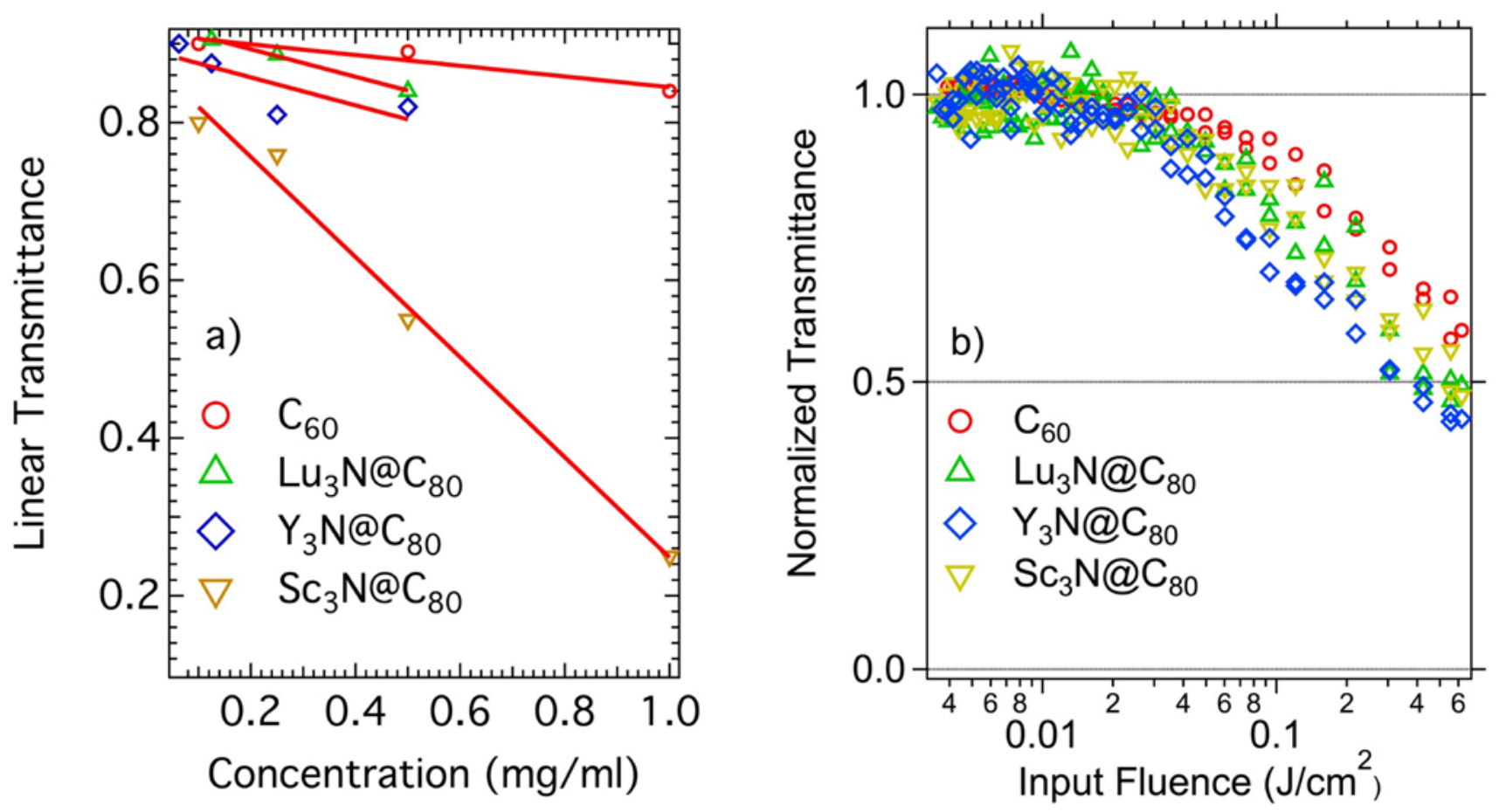

Fig. 4. (a) Linear Transmittance (measured with $1064 \mathrm{~nm}, 7$ ns laser) vs Concentration. Linear Transmittance of $\mathrm{Sc}_{3} \mathrm{~N} @ \mathrm{C}_{80}$ appears to drop faster than $\mathrm{C}_{60}, \mathrm{Lu}_{3} \mathrm{~N} @ \mathrm{C}_{80}$ and $\mathrm{Y}_{3} \mathrm{~N} @ \mathrm{C}_{80}$. (b) Non-linear optical response curve (same Linear Transmittance, 75\%) 